\title{
De la etiología a la prevención del uso y abuso de drogas recreativas
}

\author{
Amador Calafat, Montserrat Juan
}

IREFREA

Enviar correspondencia: Amador Calafat. Irefrea. Rambla, 15, 2. $3^{\text {a }} 07003$ Palma de Mallorca. irefrea@irefrea.org

\section{Resumen}

La prevención de las drogas debe guiarse por una selección adecuada de los factores de riesgo y protección. Tradicionalmente han tenido interés sobre todo los factores individuales y los comunitarios más ligados a la marginación, pobreza, etc. Pero en la actualidad el consumo de drogas recreativas depende de condiciones totalmente nuevas: la cultura recreativa nocturna de fin de semana y la industria recreativa que ha generado una oferta importantísima de este tipo de diversión, en el cual la música, el baile y el consumo de drogas recreativas ocupan un lugar importante.

Los jóvenes que participan de estas actividades lo hacen de forma muy frecuente y son preferentemente de clase media, buenos estudiantes, con baja percepción de problemas por el uso de drogas e interesados en sus efectos. Se destaca la importancia de la mujer como nueva consumidora de drogas.

Revisando la prevención en contextos recreativos hecha hasta ahora en Europa se muestra que se basa principalmente en dar información y en la reducción del daño. Se trata de actuaciones sin evaluar y que se presumen insuficientes, cuando no ineficaces -a excepción de las que directamente tratan de mejorar el contexto recreativo- por no cumplir con las exigencias de la investigación realizada en prevención. La prevención para que sea eficaz en estos ámbitos debe tener en cuenta los aspectos culturales, cuestionando directamente la lógica recreativa actual y debe conseguir un pacto con la industria recreativa.

Palabras claves: prevención, políticas preventivas, drogas recreativas, factores de riesgo, prevención comunitaria.

\section{Summary}

Drug prevention must be guided by an adequate selection of the risk and protection factors. Individual and community factors most closely linked to marginalisation, poverty etc. are the ones that were, traditionally, of particular interest but, at the present time, recreational drug use depends on totally new conditions: the weekend night time recreational culture and the leisure industry which has generated an extremely widespread supply of a kind of entertainment in which the music, dancing and recreational drug use occupy an important place.

The young who take part in these activities do so very frequently and are generally middleclass, good students with a low perception of the problems arising from drug use and of their effects. The importance of the woman as new drug user is notable.

Reviewing prevention in recreational contexts undertaken up to now in Europe, it can be seen that it is based mainly on providing information and on harm reduction. These are actions that are unevaluated and presumed to be insufficient, when not ineffective with the exception of those that directly aim to improve the recreational context- as they do not accomplish the demands of research into prevention. To be effective in these settings, prevention must take the cultural aspects into consideration, directly questioning the current recreational logic, and must reach an agreement with the leisure industry

Key Words: prevention, policy, recreational drugs, risk factors, community prevention. 


\section{INTRODUCCION}

E I uso y abuso de drogas tal como lo conocemos actualmente es un fenómeno relativamente reciente cuyo inicio podemos situar en los años 60, aunque su verdadero desarrollo tiene lugar en las últimas décadas. Si bien es cierto que muchas culturas han utilizado históricamente drogas con distintos fines, cualquier parecido con el uso recreativo de drogas actual tanto por sus dimensiones como por su significado cultural es anecdótico, si exceptuamos el uso del alcohol en el mundo occidental. Podemos decir que los seres humanos en distintas culturas y en distintos momentos históricos han buscado alterar su estado de conciencia a través de las drogas, pero ello, cuando se ha dado en el pasado, ha sido siempre de forma selectiva, ritualizada, ocasional y, probablemente casi nunca como medio para divertirse. El alcohol ciertamente si que ha sido asociado en occidente con la búsqueda de la embriaguez y de la diversión colectiva desde hace ya tiempo y es el referente histórico y actual más claro.

Con respecto a las drogas ilegales es en los años 60, y en especial en USA, donde encontramos las referencias más cercanas a la situación actual con la asociación del rock and roll y de la pop music; con celebraciones festivas y con el uso de drogas como marihuana y LSD. Entre la música reggae y el cannabis se produce la máxima sinergia de forma que los grandes conciertos con esta música implicaba automáticamente organizar la distribución de cannabis entre los asistentes. El final de los 80 y la década de los 90 implica nuevamente una estrecha asociación entre música (techno, house, bakalao,...) y drogas como el éxtasis (MDMA), junto con la expansión de una gran industria recreativa en todas las ciudades -ya no simplemente las turísticas o las grandes capitales-, con gran participación de jóvenes; y es cuando, con toda propiedad, podemos hablar de cultura recreativa y de drogas recreativas.

La relación cultural de la música con las drogas es una cuestión clara, pero compleja al mismo tiempo. Es conocida la estrecha relación que se ha ido estableciendo entre la cultura rave y techno con el éxtasis(Beck 1993;Forsyth, Barnard, \& McKeganey 1997; Gamella, Alvarez \& Romo1997;García 1999;Kokoreff \& Mignon 1994;Megías \& Rodríguez 2001). Pero obviamente no es una relación estática y de hecho distintas tribus urbanas o colectivos prefieren o se identifican más con un tipo de música y con un estilo de vida y con un determinado consumo. En un estudio (Calafat et al. 1999) realizado con 2.700 jóvenes europeos en 1.998 entrevistados en zonas recreativas se aporta información que ayuda a matizar este tema. Resulta que a los que les gusta el house, jungle, drum\&bass, y funky beats -que son mayoría entre la gente que suele salir los fines de semana- son los que más tienden a consumir cualquier tipo de drogas, mientras que los que les gusta el pop, la música melódica o la salsa son más moderados en sus consumos. Por otro lado, a los que les gusta más el rock y el reggae tienden a consumir preferentemente alcohol y cannabis, pero no éxtasis.

Es importante entender que las nuevas formas de consumo de drogas y de diversión nocturna de fin de semana se nutre en gran parte de jóvenes de clases medias. En el mismo estudio realizado en una muestra de 2.700 jóvenes europeos de 9 distintas ciudades encontramos que sólo el $16 \%$ se autodefinen como pertenecientes a una clase social media/baja o baja, el $49 \%$ son universitarios y sólo el $12 \%$ se consideran a si mismos como malos o muy malos estudiantes. Por tanto, estamos lejos de viejos estereotipos que asocian el consumo de drogas a situaciones de exclusión social. Incluso podemos decir que las nuevas tendencias recreativas y el consumo de drogas que implican se han convertido en el eje central de la socialización para una buena parte de los jóvenes en su camino hacia la integración y el éxito social. Es decir, de una forma acrítica y bajo el reclamo de la industria recreativa -que tiene una gran capacidad para captar y vehiculizar las necesidades de los jóvenes- muchos de ellos 
buscan a través de las prácticas recreativas de fin de semana aprender sobre la amistad, las relaciones sexuales, el éxito social, el riesgo, la embriaguez, etc.

J Beck (Beck \& Watson 1991) que es uno de los estudiosos del uso del MDMA entre los participantes estadounidenses del movimiento New Age, antecedente importante a la aparición del uso de esta sustancia en los contextos recreativos europeos, comenta que antes de los 60 el uso de drogas ilegales estaba asociado normalmente a grupos marginales, pero que los sesenta representan como gran novedad la expansión del uso de drogas preferentemente entre los jóvenes blancos de clase media. Pero además se produce un cambio cualitativo clave que consiste en que la nueva situación implica que la información sobre las drogas ya no es un asunto de los propios consumidores que hablan entre sí, sino que pasa a ser una cuestión que se dirime en los medios de comunicación. Los nuevos contextos o espacios en los que se consumen drogas son cada vez más difusos y diversos, no se constituyen a partir de las mismas personas cada vez, y las motivaciones y el significado de uso pueden cambiar. Es el caso en su estudio de los que utilizan el MDMA para propósitos terapéuticos o de crecimiento personal, que llaman a dicha sustancia Adam, a los que la utilizan para propósitos recreativos que la llaman éxtasis. Es decir, la sustancia pierde protagonismo frente al contexto, que viene siendo redefinido continuamente dentro de esta interacción de la droga con el significado que le da el contexto.

Y este es precisamente el gran reto de la prevención actual: ¿como intervenir para extinguir o modular un comportamiento difícil de concretar, redefinido continuamente según las vinculaciones culturales del momento, que es complicado de presentar como problemático al estar tan asociado con prácticas normalizadas de las personas sobre las que hay que intervenir?

En efecto, aunque puede parecer paradójico, es más fácil conceptualizar -y posiblemente hasta intervenir- sobre prácticas mar- ginales o claramente separadas de las conductas de la mayoría. Es el caso del Sida asociado al intercambio de jeringuillas entre heroinómanos. Pero todo se vuelve mucho más problemático cuando se trata de actuar sobre prácticas culturales legitimadas por la mayoría que son cada vez más habituales, asociadas a la diversión y al éxito social, y que además son muchas veces lideradas por la elite social. Hay que contar con que muchos de estos jóvenes están dotados de importantes habilidades sociales lo cual les posibilita minimizar en gran parte las consecuencias negativas que pueden tener para ellos el consumo de drogas, contribuyendo a crear una imagen de banalidad sobre las conductas de abuso. Pensamos que todo ello representa para muchos adultos e incluso profesionales un cierto espejismo que les dificulta ver más allá del éxito y la alegría inmanente a estas prácticas sociales.

Aparte de las medidas represivas, podemos hablar básicamente de dos tipos de respuesta preventivas a esta situación. Una sería continuista de la prevención primaria clásica (escolar sobre todo) que se ha venido realizando desde hace unas cuantas décadas. Se trata de intervenir sobre los indicadores o factores de riesgo clásicos (baja autoestima, clarificación de valores, asertividad, marginalidad,...). Este tipo de prevención no tiene muchas veces suficientemente en cuenta las nuevas condiciones de socialización y de inicio de los consumos por parte de los jóvenes en el contexto recreativo. Y, además, se suelen realizar antes de que los jóvenes estén precisamente decidiendo sobre sus conductas de consumo. Tienen a su favor que llevan años practicándose y existe abundante literatura científica, que existen evaluaciones de resultados, que, en definitiva, se sabe bastante lo que funciona y lo que no funciona.

Por otro lado, están teniendo mucho éxito últimamente en la prevención del uso recreativo de drogas entre muchos profesionales aquellos acercamientos basados en el modelo de la reducción del daño, importado de las prácticas terapéuticas realizadas con los heroinómanos. Se basan en general en dar 
información sobre prácticas de consumo menos nocivas, pues se asume la normalización de dichos consumos y la gran dificultad para influir sobre ellos. Existen aspectos importantes de estos acercamientos que hay que apoyar decididamente como pueden ser todas las intervenciones sobre el contexto recreativo tales como formar al personal de las discotecas, introducir áreas de descanso, sustituir los vasos de cristal por vasos de material plástico o similar, asegurar el transporte público, etc.. Pero hay otras prácticas (como el pill testing in situ, distribuir información sobre practicas de uso menos problemáticas, etc. ) que no han sido evaluadas, cuya eficacia tiene que ser forzosamente limitada puesto que todos los programas preventivos que han sido evaluados hasta la actualidad y se han mostrado eficaces suponen siempre una mayor interactividad y una actuación mucho más intensa y duradera (Tobler 1997; Tobler et al. 2000). Otro aspecto que suelen descuidar estos enfoques es la necesidad de combinar diversas actuaciones buscando la sinergia. Estos programas deben tener más en cuenta la diversidad de colectivos y necesidades preventivas presentes en la escena recreativa.

Ante esta situación ¿qué proponer? Evidentemente la respuesta no puede ser simple. Propondríamos empezar por un mejor conocimiento de los aspectos culturales que configuran el contexto recreativo en el que se están fraguando estas prácticas de consumo, una revisión de los factores de riesgo y protección para ver cuales son los que más se adaptan a esta forma de consumo actual, y una revisión de los programas preventivos aplicados hasta el momento. Obviamente el tipo de propuesta resultante tendrá que tener la entidad de una política preventiva que tenga en cuenta y coordine diversas actuaciones, que tenga en cuenta la cuestión cultural y las grandes implicaciones económicas e intereses existentes desde la industria recreativa y desde los productores de drogas tanto legales como ilegales.

\section{Importancia del contexto recreativo}

El término genérico drogas recreativas engloba una serie de sustancias cuya característica común no es la estructura química, ni el tipo de efecto psicotropo, sino que se distinguen por ser utilizadas frecuentemente en contextos recreativos sobre todo de fin de semana. Esto engloba evidentemente a muchas drogas (desde el alcohol y el tabaco a la marihuana o el LSD, a las llamadas drogas de síntesis, ketamina, etc.) pues casi todas ellas son utilizadas en contextos recreativos. Incluso la heroína puede ser utilizada en contextos recreativos -por ejemplo, para bajar la estimulación excesiva al final de la noche- pero al ser un hecho bastante infrecuente pues no la consideramos una droga recreativa, como tampoco lo serían los inhalantes. Lo que quiere remarcar el termino recreativo es la preponderancia que está adquiriendo, sobre todo en los países industrializados, una forma de divertirse las noches de los fines de semana, por parte de los jóvenes principalmente, preferentemente en bares y discotecas -también la calle últimamente con el fenómeno del botellón-, donde tiene un protagonismo importante la música, el baile, la interacción con los amigos,..., y, con una asociación frecuente al consumo de determinadas drogas. Es decir, el contexto en el que se consumen estas drogas pasa a tener tal importancia en las razones por las que se consume y en las pautas de consumo que ello justifica el hablar de 'drogas recreativas'.

Otro aspecto a tener en cuenta es que esta forma de divertirse, que recibe distintos nombres según los países o subculturas juveniles (en nuestro país hablamos de 'salir de marcha' y en algunos países europeos se denomina 'clubbing'), se ha convertido en una práctica muy frecuente y casi hegemónica dentro de las prácticas de diversión y de pasar el tiempo libre los jóvenes. En una encuesta realizada a 2.700 jóvenes europeos en contextos recreativos nocturnos sabemos de la intensidad y dedicación de estos jóvenes clubbers a esta forma de diversión. En 
efecto el $57 \%$ de los clubbers europeos salen 3 o 4 fines de semana al mes, el 61,4\% lo hacen entre 2 y 3 fines de semana, mientras que entre semana también acostumbran a salir por la noche el $40 \%$. Cada vez que salen acostumbran a emplear una media de 6,1 horas (Calafat et al 1999). Obviamente hay diferencias entre ciudades siendo la española que formaba parte de este estudio donde se salía con más frecuencia, durante más horas y visitando más locales cada noche. Al no utilizarse en dicho estudio muestras representativas las conclusiones siempre son provisionales. Pero podemos aportar datos sobre España a partir de una muestra representativa de 20.450 escolares entre 14 y 18 años realizada en el 2.000. En este estudio el $34 \%$ de los escolares declaran haber salido por las noches todos los fines de semana en el último año; mientras que salen todas las noches del fin de semana el $48^{\prime} 4 \%$ de los estudiantes de 18 años y el $56 \%$ de los escolares regresó a casa la última vez después de las $02^{\prime} 00$ horas (Plan Nacional sobre Drogas 2002).

Por tanto estamos ante una actividad de diversión que la practica un grupo importante de jóvenes, de forma bastante intensiva y frecuente y que desplaza a otras formas de diversión o de pasar el tiempo libre. Esta forma de diversión, ha encontrado en el progreso tecnológico potentes aliados como son el automóvil -y otros medios de transporte- y las tecnologías de la luz y del sonido. Otro potente aliado son las drogas, pues facilitan de forma extraordinaria el paso rápido desde la rutina de la semana a la lógica de la diversión nocturna de fin de semana. Las drogas en este contexto son importantes no solo por sus propios efectos sino porque facilitan sobremanera el paso a la lógica consumista de la diversión de fin de semana diseñada por la industria. Y es que las mismas drogas ilegales ya forman parte de un gran mercado extremadamente diverso en Europa y sumamente accesible. Según el Eurobarómetro 57.2 (The European Opinion Research Group 2002), realizado con 7.687 jóvenes europeos de 15 a 24 años, el 61,9\% (el 71,3\% en Espa- ña) de los jóvenes europeos declaran que les seria fácil conseguir drogas cerca de su casa, el $54,9 \%$ (el $66,2 \%$ en España) en o cerca de su colegio o universidad, el 72,3\% (el 90,1\% en España) en pubs/clubs y el 76\% (el 89,9\% en España) en parties lo cual da una visión clara de que la cuestión de la ilegalidad no tiene demasiado peso a la hora de considerar la accesibilidad de los jóvenes a estas drogas. Es seguramente por ello que en la actualidad en países desarrollados la accesibilidad a las drogas no es un factor de riesgo muy importante (Bachman et al 2002), aunque podría tener su importancia en la iniciación temprana.

Pero, es muy importante conservar una perspectiva histórica del desarrollo de esta forma de diversión y del consumo de drogas que se le asocia. Desde una perspectiva española -y sobre todo en las zonas de España más turísticas- es fácil pensar que las cosas siempre han sido así, pero ello no es exacto, y esta normalidad con que los jóvenes acuden con tanta frecuencia a las discotecas y consumen drogas recreativas es un fenómeno que tiene una existencia de unas dos décadas, y dentro de la perspectiva europea empieza con fuerza a finales de los 80, cuando empieza a afianzarse la cultura del rave y del éxtasis bajo inspiración de las incursiones veraniegas de los jóvenes europeos en las noches de los centros turísticos del mediterráneo como lbiza (Collin 1997; Hammersley, Khan \& Ditton 2002). Las razones de esta expansión hay que verlas en la mayor disponibilidad económica de los jóvenes, en la creciente oferta de la industria dirigida a los jóvenes, en el menor control al que están sometidos los jóvenes principalmente por sus familias, en el uso de alcohol y otras drogas, etc. Esta perspectiva histórica permite ver que estamos ante un fenómeno social y culturalmente construido y, por tanto, en principio, con posibilidades de intervenir sobre su devenir. 


\section{Factores de riesgo y protección}

“Realizar la prevención basada en una adecuada teoría o modelo nos permite manejar y cambiar los factores que facilitan el consumo y potenciar los que facilitan el no consumo" (Becoña, 2002). El problema reside en que son tantos los factores de riesgo y protección y tantas las combinaciones que se pueden realizar entre ellos, que lo que parece ocurrir en la práctica es que cualquiera pueda encontrar más o menos justificación a sus hipótesis haciendo una lectura más o menos sesgada de los datos existentes. Es verdad que siguen existiendo lagunas en la investigación sobre los factores de riesgo y protección porque son estudios dificíles y costosos, porque se investiga poco, porque muchos estudios son básicamente norteamericanos con una realidad social distinta -la importancia de lo recreativo y la tolerancia social son menores-, y porque la realidad social y las razones de consumir están cambiando rapidamente. Pero no obstante estas insuficiencias investigativas, hay bastantes cuestiones que están ya bien fundamentadas y que permiten indicar las lineas sobre las que trazar las prácticas preventivas. Está sobre todo claro lo que no funciona. En todo caso, no es posible diseñar programas preventivos ni establecer hipótesis causales sin tener en cuenta la investigación actual sobre factores de riesgo y protección.

Los factores de riesgo y protección son variados y de naturaleza muy distinta (genéticos, sociales, psicológicos, etc.). En la revisión que hace Becoña (2002) considera las siguientes categorías: familia, comunitario, compañeros o iguales, escolar e individual. Antes de una intervención se debería hacer un 'diagnóstico' de la población sobre la que vamos a actuar para conocer que factores de riesgo y protección están presentes. Esto evidentemente es una cuestión compleja y costosa y pocas veces tenemos las posibilidades de realizar este estudio previo con profundidad y sistemáticamente. Existen cuestionarios diseñados (Arthur et al. 1997) para cubrir un amplio abanico de los factores más fre- cuentes y que intentan cubrir esta necesidad reseñada, pero que lógicamente necesitan ser validados para cada país o región, para que el proceso cubra todos los requisitos científicos, pero en la práctica se puede ser menos exigente a la espera de que la investigación mejore. Se hacen puestas al día con alguna frecuencia para determinar cuales son los factores más relevantes de acuerdo a la investigación (Becoña 2002; Gardner et al. 2001;Robles \& Martínez1998). Obviamente esta relevancia depende de la edad del sujeto, de la presencia de otros factores, del ambiente, del consumo de otras drogas, de la cultura en que se vive, etc. La influencia de estos factores sobre la conducta de uso de drogas puede a su vez ser considerada inmediata, próxima, lejana o remota (Petraitis et al. 1998). Por tanto no es fácil dar su justo lugar y peso a todo este entramado de factores, lo cual obliga siempre a tener que trabajar con hipótesis de las que dependen la mayor o menor importancia que concedemos a cada factor.

\section{Factores comunitarios}

Normalmente los factores de riesgo y protección más conocidos y que se han tenido más en cuenta en la construcción de programas preventivos son los individuales pues son los más fáciles de estudiar, coinciden más con la formación de los profesionales que se dedican a la prevención y son los que más conectan con la visión que normalmente la gente puede tener acerca de por qué la gente se droga (ser mal estudiante, desinterés por las cosas, malas compañías, pobreza, problemas familiares, etc.). Entre estos factores individuales más conocidos y más utilizados tenemos la conducta antisocial, la rebeldía, la baja autoestima, el fracaso escolar, la pobreza, la búsqueda de sensaciones, el inicio temprano en el consumo, el consumo de otras drogas, la baja asertividad, la depresión, etc. Pero si queremos explicar el gran crecimiento que están teniendo en España y en 
Europa las drogas recreativas desde hace una o dos décadas no parece que haya que buscar la razón en que de repente los jóvenes se hayan convertido en más rebeldes, o más antisociales, o con peor autoestima. Precisamente en un intento de conocer cuales son los factores que mejor explican los cambios anuales o plurianuales (es decir, las subidas o bajadas que siguen ciclos de varios años) en el consumo de una determinada droga Bachman (Bachman, Johnston \& O'Malley 1998) descubre que es la percepción del riesgo y la desaprobación de su uso el factor clave. Si buscamos la explicación de un caso individual siguen siendo de interés los factores de riesgo clásicos (estudiar más o menos, cumplir con la religión, participar en actos delictivos, ...), pero los grandes cambios, es decir, que la bajada del consumo de marihuana, por poner un ejemplo, en los 80 y la subida significativa de los 90 no dependería de cambios en la psicología o la problemática de los jóvenes, sino en su percepción de si la marihuana produce problemas y la actitud ante su consumo. Y esto nos ayuda a entender mejor cuales son los factores de riesgo que debemos tener en cuenta a la hora de estudiar -y a lo hora de proponer solucionesel consumo creciente de drogas recreativas. Tendremos que buscar no tanto por el lado de los factores individuales sino básicamente en cambios en los factores comunitarios como son el importante desarrollo de la oferta recreativa por parte de la industria, la mayor disponibilidad económica de los jóvenes, la baja percepción de riesgo, la tolerancia social, la legitimación social de las drogas, etc. Entendemos pues que son los factores de riesgo y protección comunitarios los que nos interesa más explorar y ponderar al planificar la prevención del consumo de drogas recreativas.

El estudio de los factores de riesgo comunitarios es sin embargo más complicado de realizar que el de otros factores más concretos como pueden ser el consumo de drogas de los familiares, o la autoestima o la búsqueda de sensaciones como rasgo psicológico. Los elementos comunitarios y culturales son más amplios y difíciles de definir en términos operativos, son más variables en el tiempo y en el espacio y, en definitiva, más difíciles de medir. Los factores de riesgo que son más frecuentemente tenidos en cuenta en relación con lo comunitario son la 'deprivación económica y social', 'desorganización comunitaria o en el vecindario', 'fracaso escolar', 'disponibilidad de drogas', 'leyes y normas favorables al uso de drogas' (Hawkins, Catalano \& Miller 1992; Kumpfer et al. 1998;Petterson, Hawkins, \& Catalano 1992). Si exceptuamos este último factor, que si se adecua plenamente a las circunstancias actuales de consumo en el contexto recreativo europeo, el resto de factores se refieren a circunstancias que poco tienen que ver con el uso de drogas recreativas en la actualidad. La pobreza, por ejemplo, ha sido uno de estos factores que tradicionalmente consiguen fácil consenso entre la población, los políticos e incluso los profesionales. Y sin embargo ni la pobreza por si sola puede explicar el futuro consumo de las personas que estén en dichas circunstancias, sino que necesita para tener su influencia de la presencia de otros factores (Hawkins, Catalano \& Miller 1992), ni tiene mucha relación con los consumos recreativos que están más relacionados, como hemos señalado antes, con poblaciones económicamente pudientes y socialmente integradas, aunque bien es cierto que el trapicheo es bastante frecuente entre una parte de estos consumidores recreativos. Además esta venta al por menor, destinada muchas veces a mantener el autoconsumo y los elevados gastos derivados de participar en la conducta recreativa, no representa muchas veces en los contextos recreativos un factor de exclusión sino que puede ser incluso un signo de estatus.

Si aceptamos pues que la explicación de la importante expansión del consumo recreativo no depende tanto de factores individuales, ni tampoco de factores comunitarios relacionados con la marginalización (pobreza, la desorganización social, etc.) seguiremos profundizando en la cuestión acudiendo nuevamente a otro estudio de Bachman et al 
(2002). En un extenso estudio en que han hecho un seguimiento de 22 cohortes -cada una de ellas es una muestra representativa de los jóvenes de Estados Unidos- durante 14 años (desde los 18 hasta los 32) a cada una de las cohortes, comenzando el primer estudio longitudinal en 1976, llegan a la conclusión de que exclusivamente hay cuatro variables mediadoras para explicar las variaciones en los consumos de año en año para cada uno de los individuos, como de las cohortes en su conjunto. Estas variables tienen distinta importancia o funcionan de distinta forma para cada individuo básicamente según se trate del periodo de amplias libertades de las que gozan los jóvenes al final de la adolescencia y principio de la juventud en la sociedad americana y el cambio importante que supone asumir roles adultos (trabajar, casarse, tener hijos, abandonar el hogar familiar), lo cual tiene consecuencia sobre los consumos. Es dentro del contexto de estas amplias libertades que supone el final de la adolescencia (19 o 20 años) donde se producen un incremento de los consumos y que cuando se llega a los 23-24 años se produce un creciente descenso al asumir roles adultos, todo ello mediatizado por cuatro variables. Estas variables son:

- la religiosidad y la asistencia a los servicios religiosos

- la frecuencia con que se participa en actividades recreativas (salidas nocturnas, fiestas o irse de copas)

- disponibilidad percibida para conseguir las drogas.

- riesgo percibido respecto a las sustancias a consumir y desaprobación expresa de su uso

Cada una de estas variables ha sido encontrada relevante a la hora de explicar las variaciones en los consumos tanto entre las distintas cohortes, como dentro de una misma cohorte al ir envejeciendo. Esta bastante establecido como la religiosidad -sobre todo si es activa- se correlaciona con menor consumo de drogas, como ocurre también en este estudio. A mayor incremento de prácti- cas religiosas, como ocurre cuando los jóvenes incrementan sus responsabilidades familiares cuando se casan o cuando tienen hijos, disminuye el consumo. Otra variable que influye en el consumo es participar en actividades recreativas, es decir, cuanto más se sale más se consume. Según pasan los años se tiende a salir menos y, en consecuencia, a consumir menos; pero si por alguna circunstancia, como suele ser si hay una separación de la pareja, se vuelve a salir más aumenta automáticamente el consumo. Lo que interesa destacar y extrapolar de cara a nuestra realidad recreativa europea, es que en este estudio el participar en actividades recreativas "tiende a alentar y a facilitar el uso de sustancias, y que estos efectos son mayormente independientes del efecto que puedan tener las actitudes que se tengan sobre las drogas" (Bachman et al 2002). Es decir las conductas recreativas por si solas explican una parte de la disminución o descenso en el consumo.

La tercera variable considerada es la disponibilidad percibida de drogas y su consumo. No es una variable muy decisiva en dicho estudio dado seguramente el elevado nivel de acceso a las drogas ilegales en nuestras sociedades, que convierten esta variable en cada vez menos discriminativa. Es posible que a edades más tempranas tenga un mayor peso que el encontrado en este estudio. Sin embargo, la variable percepción del riesgo en consumir una droga determinada, junto con la desaprobación de su uso, si que son variables muy potentes en este estudio de Bachman et al. para determinar el uso de drogas. Encuentran que esta percepción va variando dentro de una misma cohorte a medida que pasan los años, es decir que tanto la percepción negativa como la desaprobación del uso de una determinada droga aumenta a partir de los 21 años, sobre todo si hay circunstancias determinantes que supongan la asunción de roles de adultos. Pero además hay variaciones entre las diversas cohortes y en este sentido la percepción del riesgo de consumir cannabis se va incrementando desde 1980 hasta 1991 -y por 
consiguiente desciende el consumo-, mientras que a partir de esta fecha no ha hecho más que disminuir la percepción de riesgo de diversas drogas (como la cocaína y la marihuana) y por tanto aumentar su consumo.

En el caso español se puede documentar (ver gráfico 1) el mismo fenómeno desde que disponemos de series bianuales que se realizan en muestras representativas de la población escolar española de 14 a 18 años (Plan Nacional sobre Drogas 2002). Como muy bien concluye (Becoña 2002) una serie de factores de protección identificados en los estudios de (Bachman et al. 2002) como son el asumir roles de adulto (casarse, tener hijos, comenzar a trabajar,...) seguramente tendrán menos fuerza entre los jóvenes de nuestro país, especialmente cuando tienen más de 23 años, pues se ha ido retrasando la edad de casarse, tener hijos, al mismo tiempo que se dedica más tiempo a la vida recreativa.

Los datos que aportamos en la tabla 1 hacen referencia a la percepción de peligrosidad sobre diversas pautas de consumo de sustancias psicoactivas por parte de jóvenes que frecuentan ambientes recreativos de fin de semana, entrevistados precisamente en dichos contextos recreativos. En la tabla se recogen la comparación de una muestra europea y de otra española (Calafat et al. 2000), aunque dicha comparación solo puede ser entendida a título orientativo pues las muestras no son representativas. La primera cuestión que podemos constatar es que la percepción de peligro no es muy alta en general (especialmente para el alcohol, la marihuana y el tabaco, pero incluso para sustancias como el LSD o el éxtasis) y en segundo lugar que para todos los ítems la muestra española tiene siempre una visión menos peligrosa que la de la muestra europea. Otras cuestiones que podemos destacar es como la marihuana es vista significativamente como menos peligrosa que el tabaco y como el consumo de cuatro consumiciones alcohólicas en una sola sesión de consumo es visto como menos peligroso que el consumo diario de dos consumiciones. Estos datos son consistentes con los del Eurobarómetro (The European Opinion Research Group, 2002) donde un 7,4\% de los jóvenes europeos no ven ningún problema en el consumo de alcohol, un 9,6\% no lo ven en el consumo de tabaco y hasta un $11,5 \%$ no lo ven en el consumo de cannabis.

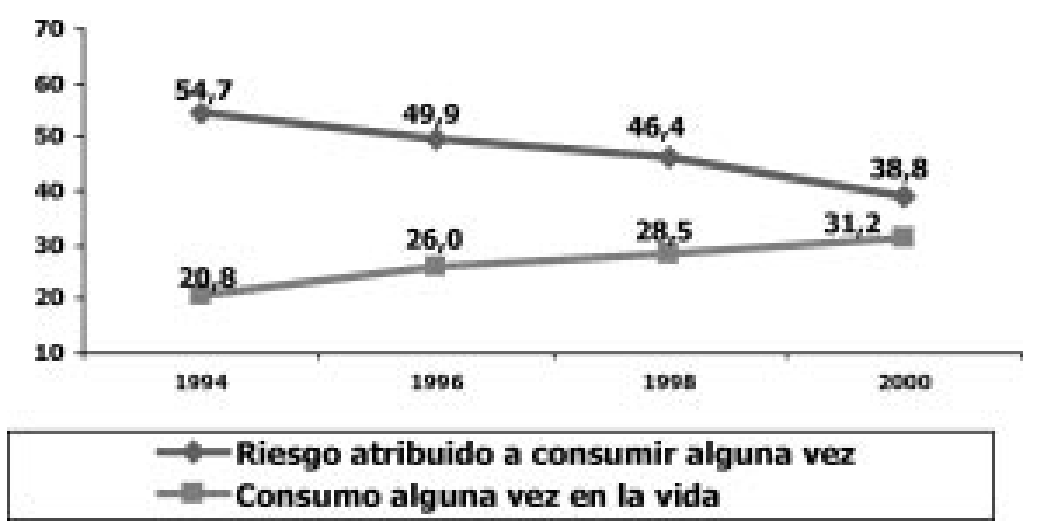

Gráfico 1. Evolución del riesgo asociado y de las prevalencias del consumo de cannabis. España, 1994-2000.

Fuente: Encuestas sobre Drogas a la Población Escolar. Plan Nacional sobre Drogas 
Tabla 1. Percepción peligrosidad de jóvenes que frecuentan ambientes recreativos de fin de semana de diversas pautas de consumo. Comparación de una muestra europea y otra española (Calafat et al 1999;Calafat et al 2000)

\begin{tabular}{lll} 
& Muestra europea (n 2700) & Muestra española (n 1340) \\
\hline Un paquete de cigarrillos al día & $68,9 \%$ & $62,6 \%$ \\
\hline Fumar marihuana con regularidad & $55,9 \%$ & $44,2 \%$ \\
\hline Éxtasis cada fin de semana & $89,4 \%$ & $87,3 \%$ \\
\hline LSD una vez al mes & $84,7 \%$ & $79,1 \%$ \\
\hline Dos bebidas alcohólicas por día & $55,3 \%$ & $40,8 \%$ \\
\hline Cuatro bebidas alcohólicas en cada ocasión & $50,5 \%$ & $36,4 \%$ \\
\hline
\end{tabular}

La construcción de la percepción del riesgo por cada individuo es seguramente un proceso complejo en el que intervienen diversas variables como la información disponible, el consumo de los amigos, expectativas, experiencias pasadas, clima social, etc. y es un tema obviamente clave para las teorías sobre la conducta de riesgo (Cummings, Becker \& Maile 1980; Rogers 1984;Weinstein 1993). A la vista de estos grandes cambios experimentados en las últimas décadas por la percepción del riesgo de diversas drogas y diversas pautas de consumo, que afectan directamente al consumo recreativo, parece obvio que los factores sociales son muy importantes en la construcción de estas percepciones. Y también parece obvio que la prevención tendrá que interesarse por un tema tan central para el consumo.

Un tema que se relaciona con la percepción de riesgos es el posicionamiento de cada individuo -y cada colectivo- en la asunción de riesgos. La vida supone necesariamente riesgos como bien sabemos, pero la actitud ante el riesgo no es la misma para cada uno de nosotros, pues hay personas que tienden a evitarlos al máximo mientras que otros encuentran una cierta excitación cuando se involucran en conductas que implican riesgo. Como bien explica Bandura (1986) a través de su concepto de auto-eficacia, los individuos necesitan tener la creencia de que cuando se involucran en una determinada conducta lo van a hacer seguramente con éxito. Y esto es valido tanto para las personas prudentes como para los que les gusta el riesgo de usar y abusar de las drogas. Son pocos los que abusan con la idea clara de que están asumiendo riesgos que no controlan, pues la mayoría cree que más o menos los riesgos por los que pasan o pueden pasar forman parte de lo previsto y de lo que pueden controlar (Calafat et al, 2001). La asunción de riesgos además ha adquirido un cierto carácter normativo dentro de la cultura recreativa, ya no siendo la expresión de una rebeldía sino una táctica para asumir objetivos convencionales(Parker, Aldridge, \& Measham 1998).

El hecho de consumir drogas lleva a los individuos a disminuir su percepción de riesgo. Pero incluso el tener problemas reales con el consumo de drogas no supone el abandono de dicha práctica. En un estudio realizado con 1.121 ravers holandeses (van de Wijngaart et al. 1997) ninguno de los que habían tenido problemas con el éxtasis lo había abandonado aunque algunos decían que tomaban menos. En el estudio de Irefrea realizado en 1.988 con 2.700 jóvenes europeos que solían salir a divertirse (Calafat et al 1999) resultó que un $29,3 \%$ de la muestra admitió haber tenido problemas con alguna droga y haber seguido consumiendo. De lo que se deduce por lo menos dos cosas: una que los problemas son frecuentes con las drogas y que la experiencia directa de que una droga puede producir problemas no significó su abandono. Las drogas con las que habían tenido problemas fueron un 36,9\% con el alcohol, un $19,9 \%$ con el cannabis, un $14 \%$ con el éxtasis, un $7,1 \%$ con el LSD, un 
$6,2 \%$ con el tabaco, un 5,9\% con la cocaína, un $3,5 \%$ con las anfetaminas y un $2,1 \%$ con la heroína.

\section{Consumidores y no consumidores de dro- gas}

De acuerdo con los datos proporcionados por el Eurobarómetro (The European Opinion Research Group, 2002) las motivaciones de los jóvenes para consumir drogas es para un $61,3 \%$ la curiosidad, para un $46,4 \%$ la presión de los amigos, para un 40,6\% la búsqueda de emociones, para un 21,5\% los efectos esperados, mientras que para un $29,7 \%$ pueden ser los problemas en casa. Vemos como en general priman motivaciones lúdicas como corresponde precisamente a lo que estamos estudiando que es el uso recreativo de drogas. Pero interesa ir más allá de esta visión, para centrarnos en las motivaciones tan contrapuestas que demuestran consumidores y no consumidores, que empezaremos analizando a partir de las motivaciones para beber alcohol en la encuesta escolar española del 2.000 según se trate de consumidores o no (Plan Nacional sobre Drogas, 2002).

\section{Motivaciones para beber entre los que beben}

- Les gusta el sabor (73\%)

- Diversión y placer (58’5\%)

- Olvidar problemas personales (15\%)

- Sentir emociones nuevas (12'9\%)

- Superar la timidez, relacionarse $\left(11^{\prime} 2 \%\right)$

\section{Motivos para no beber los que no beben}

- Efectos negativos para la salud (58'5\%)

- Pérdida de control y efectos desagradables (45’5\%)

- Riesgo de provocar accidentes (33’3\%)

- Efectos molestos (30'9\%)
Vemos que existe una lógica distinta entre ambos grupos para analizar los efectos y las consecuencias del uso de las drogas en este caso concreto el alcohol, lo cual conecta con las distintas decisiones que toma cada uno de los colectivos. Para los consumidores lo que prima claramente es el uso de la droga como un instrumento, como una tecnología, que sirve para conseguir unos fines determinados del tipo divertirse, disfrutar con sus efectos y su sabor o incluso para superar u olvidar dificultades personales como pueden ser la timidez o determinados problemas personales. Mientras que los no consumidores parten de distintas premisas a la hora de analizar los efectos de las drogas. Como vemos no les interesan los beneficios que puedan proporcionarles sino que se centran sobre los posibles efectos negativos que puedan tener sobre la salud o sobre sus posibles efectos desagradables o molestos. Esta cuestión la consideramos central a la hora de planificar la prevención pues vemos de que forma los consumidores se despreocupan de intereses preventivos, mientras que los no consumidores precisamente se sitúan en una posición preventiva y de preocupación hacia la conducta consumidora.

Estas diferencias entre consumidores y no consumidores son bastante consistentes puesto que las encontramos también en otras investigaciones. En un estudio en 1.997 con 1.642 jóvenes de 5 ciudades europeas mayores de 18 años se explora la representación social que tienen del éxtasis los consumidores de éxtasis y los que no lo eran pero compartiendo las otras características sociodemográficas y de frecuencia de salida(Calafat et al. 1998). Se descubre que tanto consumidores como no consumidores ven el éxtasis a través de dos cadenas asociativas o de representaciones sociales: los supuestos "efectos" y su supuesta "peligrosidad", para situarse a favor o en contra según se trate de consumidores o no de éxtasis. Los consumidores tienden a interesarse y a valorar positivamente los efectos de dicha sustancia, al contrario de los no consumidores que no tienen tal interés ni valoran tan positivamente 
los efectos, mientras que los consumidores muestran menos preocupación por los supuestos peligros del éxtasis que los no consumidores para los que esto es una cuestión clave. Esta actitud poco interesada en tomar precauciones y centrada sobre todo en conseguir los efectos deseados al consumir la sustancia es coherente con otro hallazgo del mismo estudio donde un $33 \%$ de los usuarios de éxtasis no les importa conocer la composición de las pastillas, otro 56\% preferirían conocerla pero la toman de todas formas y sólo un $11 \%$ dicen que si no conocen la composición (suponemos que porque confían con el proveedor o alguna razón similar) prefieren no tomarla.

La cuestión de las diferencias de los consumidores y los no consumidores (junto con los consumidores moderados) que frecuentan los espacios recreativos es abordada en un estudio reciente de IREFREA (Calafat et al 2003) a partir de una muestra de 1.777 jóvenes que han sido encuestados en ambientes recreativos y que se reparten entre 10 ciudades europeas. Todos ellos son jóvenes que salen con frecuencia a divertirse los fines de semana en clubs, pubs, discos, y la mitad de la muestra son no consumidores o consumidores muy moderados y la otra mitad cosumidores de alcohol y otras drogas. El estudio cuantitativo se complementa con un estudio cualitativo mediante entrevistas en profundidad y grupos de discusión. Como resultados del estudio vemos que aunque ambos colectivos comparten el mismo espacio recreativo y les gusta salir de marcha, sin embargo tienden a funcionar como grupos separados. La tendencia más generalizada es que consumidores y no consumidores orientas sus relaciones hacia otros amigos con sus mismos hábitos de consumo. Los no usuarios (que engloban en este estudio a los consumidores moderados como se ha dicho) tienen entre sus amigos a muy pocos que utilicen drogas ilegales. Como mucho se trata de consumidores de alcohol, tabaco y cannabis, siendo esta última droga la línea de corte entre drogas permitidas por ellos, no sintiéndose cómodos con consumidores de cocaína, pas- tillas, etc. Entre las razones aducidas para no compartir amistad con consumidores alegan en la parte cualitativa del estudio que:

- Han tenido experiencias negativas con consumidores. Los no-consumidores se sienten molestos por las actitudes que adoptan sus amigos consumidores, en situaciones en que interviene la violencia, agresividad o actitudes de riesgo, sobre todo a partir de ciertas horas de la noche.

- La conducta de los consumidores les parece extraña cuando están bajo los efectos de las sustancias, a veces por sus maneras poco respetuosas, otras porque dan significado distinto a las acciones y actitudes.

- La comunicación entre unos y otros se hace difícil. Los elementos de la interacción adquieren sentido distinto. La comunicación oral y no oral, los temas tratados, los intereses, están en una sintonía distinta.

- Las actividades relacionadas con la diversión cambian según se consuma o no. Cada colectivo busca espacios donde poder conectar mejor con sus amigos y con el ambiente, y esa conexión está bastante influenciada por el consumo. Los consumidores, quienes buscan contextos donde el consumo sea habitual, donde cierta música y baile se acople con los efectos de las sustancias, donde las acciones y actitudes de la mayoría estén en sintonía. Esa búsqueda de ambientes más coherentes hace que las actividades y espacios sean algo distintos para cada colectivo, aunque existen bastantes espacios compartidos donde interconectan y se encuentran los distintos colectivos.

La actitud mas favorable de los no-consumidores hacía el control legal de las drogas se convierte también claramente en un elemento diferenciador respecto al colectivo de consumidores. Los no consumidores tienen una actitud más favorable hacia una legislación estricta en materia de alcohol y otras drogas en general $(71 \%$ vs. $31 \%$ respectivamente) y de las drogas ilegales en particular 
(73\% vs. 63\%). Su actitud también es más favorable hacia la restricción de la venta de alcohol a menores (74\% vs. 58\%), hacia el castigo del consumo público de drogas ilegales $(72 \%$ vs. $37 \%)$ y alcohol ( $51 \%$ vs. $26 \%)$, y por un mayor grado de información acerca de la legislación sobre alcohol y drogas $(81 \%$ vs. $71 \%)$. Todo ello tiene evidentemente abundantes repercusiones prácticas sobre el uso de la normativa legal en términos preventivos

La implicación en conductas de riesgo también es distinta para cada colectivo. Conducir vehículos bajo los efectos del alcohol o viajar en un vehículo conducido por alguien bebido son las conductas de riesgo más practicadas por los consumidores y una de las conductas que más les diferencia de los noconsumidores. El 43,1\% de los consumidores ha conducido bajo la influencia del alcohol mientras que entre los no consumidores lo ha hecho el $13 \%$; el $79,6 \%$ de los consumidores han viajado en un vehículo conducido por alguien bajo la influencia del alcohol, a diferencia de un $48 \%$ de no-consumidores que también lo ha hecho. Otra de las razones que diferencia claramente a consumidores de no consumidores es la importancia que dan para salir de clubbing a buscar sexo (un $35.2 \%$ de los consumidores frente al $25.6 \%$ de los no consumidores).

\section{Genero}

Uno de los aspectos novedosos dentro de la nueva cultura recreativa es la incorporación masiva de la mujer al uso de drogas. A nivel europeo, de acuerdo al último Eurobarómetro (2002) que aborda la cuestión del consumo de drogas entre los jóvenes, encontramos que el consumo de cannabis el último mes es de $15,2 \%$ de varones y $7,4 \%$ de mujeres, mientras que el consumo de otras drogas ilegales es de $3,3 \%$ entre los hombres y el $2,1 \%$ entre las mujeres. En cuanto al consumo regular de tabaco nos encontramos con un $38,8 \%$ de hombres y un $34,9 \%$ de muje- res; y en relación con el consumo regular de alcohol hay un $29,5 \%$ de hombres y un $20,8 \%$ de mujeres. Pero si a nivel europeo todavía existen diferencias de consumo a favor de los hombres a pesar del avance experimentado por el consumo de la mujer, ya hay países en la Unión Europea en que ya encontramos más mujeres consumidoras de alcohol y tabaco. Por ejemplo en España en la población escolarizada de 14 a 18 años a partir de la encuesta escolar de 1996 -y también en la de 1998 y en la del 2000- las mujeres superan a los hombres en 'haber consumido alguna vez en la vida', en consumo el último año y en consumo en el último mes de alcohol. En la encuesta del 2000(Plan Nacional sobre Drogas 2002) el porcentaje que había consumido alcohol en el último mes era entre las estudiantes del $58,3 \%$ y entre los estudiantes del $57,8 \%$ y en cuanto al consumo de tabaco el último mes era de $35,8 \%$ entre las mujeres y de $25,2 \%$ entre los hombres. Pero sigue siendo cierto que entre los consumidores los varones tienden a abusar más. Por ejemplo en el caso del tabaco entre los que consumen más de 10 cigarrillos diarios hay $20,9 \%$ de hombres y un $15,8 \%$ de mujeres, a pesar de que hay un $72 \%$ de mujeres consumiendo diariamente frente a un $68,3 \%$ de varones entre los que han consumido tabaco durante los últimos 30 días.

Todos estos cambios tienen lugar en relación con el cambio de rol y de la definición de la identidad femenina durante las últimas décadas. La nueva cultura recreativa no sólo es un exponente de esta nueva situación, sino que seguramente está siendo clave en su definición. Debemos considerar que una parte importante de la socialización de los jóvenes tiene lugar actualmente en el contexto recreativo. De aquí la importancia de profundizar en como se construye socialmente esta identidad femenina pues ello tiene sin lugar a dudas su conexión con las pautas de uso y abuso de drogas. Se habla de la hipótesis convergente para designar esta situación en que las pautas de consumo de ambos sexos se están aproximando. Esta convergencia es más clara a medida que compara- 
mos muestras más jóvenes. Seguramente no sólo es un factor cultural el que lleva a las mujeres a consumir como sus compañeros del otro sexo, sino que también debe influir el estrés creciente que supone para la mujer la asunción de sus nuevos roles y las altas exigencias sociales a las que se ven sometidas. En un reciente estudio europeo(Bloomfield 2002) sugieren que el incremento del uso de alcohol en mujeres profesionales tiene que ver con la presión generada por los deberes familiares y profesionales, junto con la necesidad de adaptarse a los ambientes hasta hace poco exclusivamente masculinos. Cualquier acción preventiva deberá por tanto introducir la perspectiva de género.

\section{Prevención recreativa en Europa}

Hay algunas revisiones acerca de los programas preventivos realizados en los últimos años en Europa (Burkhart \& López 2002; Calafat A et al. 2003; Calafat et al 1998;Tossmann, Boldt, \& Tensil 2001). El panorama no ha cambiado prácticamente en cuanto a orientación desde la primera revisión que corresponde a la situación en 1.997 donde se destacaba que la estrategia básica era principalmente de tipo informativo y orientada a la reducción del riesgo y comenzaban los proyectos en que se utilizaba a los pares para proveer información. Esta es la situación general, pero si es verdad que empieza a notarse una mayor diversidad de programas que no son mayoritarios pero que ensayan otras fórmulas como puede ser programas en los que se realiza counselling, intervención en crisis,... Pero quizás lo más novedoso sean las medidas con las que intentan hacer el contexto recreativo tanto físico como humano más saludable (Club Health, Safer dance, ...). También es de destacar la importancia que adquiere progresivamente internet en la información que reciben los jóvenes. Existen páginas institucionales cada vez con mejor información, pero no cabe duda de que también estamos asistien- do a la proliferación de páginas donde se informa de una forma sesgada y se defiende el uso de drogas.

La situación en cuanto a evaluación de resultados era y sigue siendo la misma, es decir no hay, aunque hay más programas que aplican evaluación del proceso, lo cual hace muy complicada la situación pues los programas están expandiéndose sin que podamos realmente saber si son eficaces.

La última revisión (Calafat et al 2003) se basa en el análisis cualitativo de 40 programas preventivos implementados en diez países europeos (Reino Unido, Portugal, Grecia, Finlandia, Alemania, España, Austria, Francia, Italia y Países Bajos). Los programas seleccionados se consideran entre los más populares y de mayor alcance en cada país. No se trata pues de una revisión sistemática, pero si que permite indicar por donde van las prácticas más habituales en Europa.

Los programas revisados están orientados hacia grupos de edad muy diversos. En su conjunto abarcan un colectivo muy amplio, desde los 6 años hasta el grupo de adultos sin especificar edad límite. El grupo de edad mejor representado es el que va de los 14 a los 20 años. El 63\% de los programas se dirigen a consumidores y no consumidores indistintamente, mientras que un $37 \%$ tiene como población diana el grupo exclusivo de consumidores. Es importante destacar también que no se ha realizado distinción entre consumidores experimentales o habituales ya que, casi la totalidad de los programas se referían a ambos colectivos de consumidores. Sabemos que hay importantes diferencias entre ambos y que, por tanto, el discurso preventivo debe ser diferenciado. El programa inglés 'Decubed' (safer dance) realiza materiales diferentes para el grupo de no consumidores o consumidores moderados y para el grupo de consumidores, estos últimos basados en la reducción de daños. Sin embargo ha sido la única excepción encontrada en la muestra. La variable género tampoco es un aspecto que sea tenido en cuenta por los programas a la hora de diseñar estrategias o mensajes diferenciados. Se han encon- 
trado contadas excepciones en los programas analizados en el estudio, como el programa alemán 'Model project for ecstasy prevention with special emphasis on a peer educational and gender specific approach'.

Los programas cuya población diana se refiera a grupos con características concretas diferenciadas del resto de la población recreativa son escasos. El programa de mediación entre iguales '....And What About you?' cuyo objetivo es disminuir el policonsumo de alcohol con otras drogas entre los turistas que visitan dos localidades concretas de España y Grecia sería un ejemplo de especificidad. Otro ejemplo de enfoque delimitado es el programa 'Prevention of use and abuse of psychoactive susbstances in sky resorts' de Francia que pretende prevenir el consumo de drogas entre los trabajadores temporales de las estaciones de ski. También en Alemania los programas 'Jugendcafé GAK' y 'Zeynom, Drogenfreies Café' incorporan la atención a inmigrantes en sus servicios de counselling profesional en el marco de espacios de encuentro libres de droga.

Podemos ver en la Gráfica 1 cuales son los grupos intermediarios más frecuentes, es decir aquellos grupos o colectivos que serán los que finalmente realizarán el programa con los destinatarios finales, que normalmente suelen los jóvenes. Entre estos intermediarios tenemos a los propios jóvenes, a grupos de profesionales (trabajadores sociales o de la salud y educadores), la familia, algunas ONGs e incluso los propios trabajadores de la industria recreativa (staff de discotecas, dj's,...).

Como es de esperar (ver Gráfico 2) en programas de prevención recreativa las discotecas son escogidas como lugar de implementación prioritario por un $34.1 \%$ de los

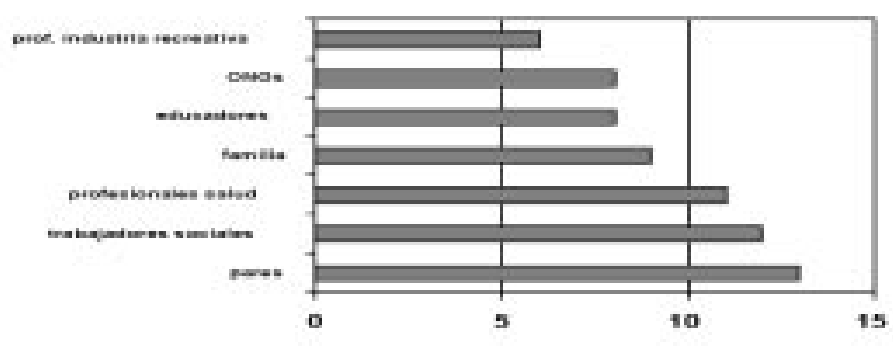

曰" p*omamas

Gráfico 2. Grupos o colectivos intermediarios a los que se dirigen los programas

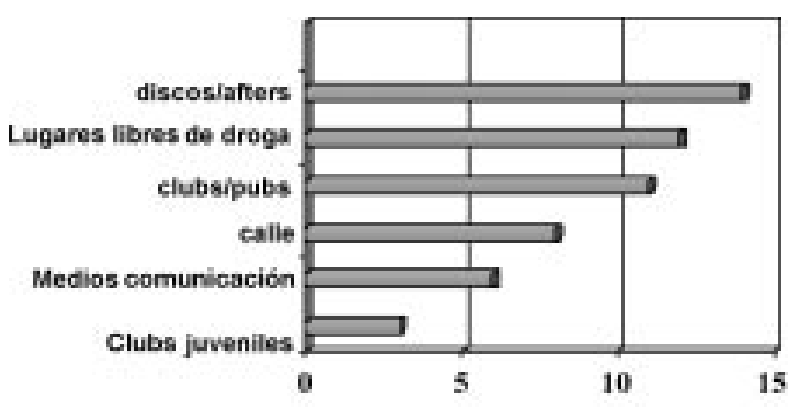

口n' programas

Gráfico 3. Lugares donde se desarrollan los programas preventivos europeos estudiados 


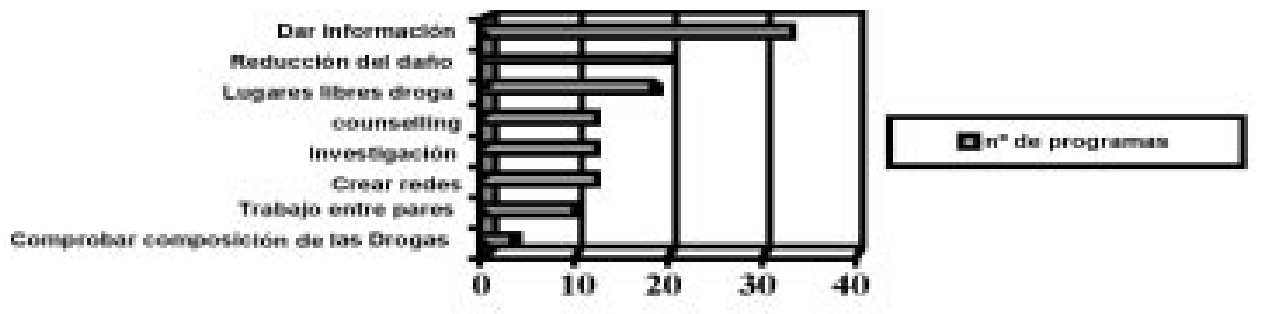

Gráfico 4. Objetivos generales más frecuentes de los programas preventivos recreativos europeos

programas y los pub y bares de la noche por un $26.8 \%$. El $29.2 \%$ de los programas ofrecen lugares libres de droga. Pero también hay programas que tienen como escenario la calle y los club deportivos.

El gráfico 4 muestra los objetivos generales más frecuentes presentados por los programas. 'Proporcionar información sobre drogas' $(80.4 \%)$ y 'reducir los daños derivados del consumo de drogas' (48.7\%), son los objetivos mencionados con mayor frecuencia por los programas que integran la muestra. El $43.9 \%$ de los programas tienen como objetivos 'ofrecer lugares libres de drogas'. El $29.3 \%$ ofrecer 'counselling profesional', 'actividades de investigación y recogida de datos' y la creación de redes. El $24.4 \%$ son programas de educación entre pares $y$, por fin, tres de los programas pertenecen al grupo de testing de drogas.

Una de las aportaciones españolas más genuinas a este abanico de actividades preventivas es la organización de actividades alternativas sin drogas por las noches de fin de semana. Un ejemplo de este tipo de programas pionero en España es el programa 'Abierto hasta el amanecer', sobre cuya evaluación haremos referencia más adelante. Su primera edición fue en 1997, actualmente se implementa por lo menos en seis regiones españolas. En estos pocos años son numerosos los municipios españoles que han puesto en marcha programas similares. Pero la impresión es que esta importante inversión debería ir acompañado de una mayor evaluación, pues es algo novedoso y no está exento a priori de la posibilidad de actuar contrapreventivamente. Hace falta pues más delimitación y evaluación de objetivos y de resultados de los programas de ocio alternativo antes de seguir promocionándolos. Su existencia no puede suponer el abandono de otras formas de prevención y su verdadero sentido debe estar dentro de políticas de prevención más amplias que por lo menos:

- aseguren la existencia de posibilidades recreativas diurnas para los jóvenes

- Hagan cumplir las medidas legales (horarios, venta a menores, consumo en la vía pública, publicidad, ...)

- Apliquen medidas de 'reducción de riesgos' en los locales recreativos (formación porteros, cristales, agua.. ) y se trabaje junto con la industria recreativa para hacer de los espacios recreativos unos espacios más saludables.

En otros países se van desarrollando distintas iniciativas que merecen un seguimiento detallado de su funcionamiento y resultados. En Alemania existe una tradición desarrollada, según el informe del Observatorio (EMCDDA 2002), para "la cooperación entre los clubes deportivos y la prevención de drogas desde 1994. En 2000, recibieron formación 2500 líderes deportivos juveniles'. En Ita- 
lia, a raíz de la alarma creada por la muerte de dos adolescentes supuestamente por MDMA, el estado italiano obliga a la asociación de empresarios de discotecas (Sindacato Imprenditori Locali da Ballo) a firmar en febrero del 2001 un convenio de colaboración entre el gobierno y dicha asociación para mejorar la prevención en las discotecas. En el Reino Unido se ha publicado una guía para salir de fiesta con seguridad 'Safer Clubbing'(Webster, Goodman, \& Whalley 2002) en la cual se recogen los principales objetivos y recomendaciones a seguir para la protección de la salud. Se trata de un documento basado en los códigos de prácticas aprendidas a lo largo de años y especialmente el 'Dance till Dawn Safely', producido por el London Drug Policy Forum in 1996. Con anterioridad se han publicado guías con la misma finalidad en Australia, nueva Zelanda y South Africa.

\section{¿Qué prevención?}

"La prevención de drogas como una tarea profesional surge en las sociedades plurales donde los valores y los estilos de vida tradicionales ya no son capaces de garantizar formas generalmente aceptadas de uso de sustancias" (Grund 1993). Esto sin lugar a dudas ocurre con la cultura recreativa actual cuya lógica no sólo no garantiza un uso ritualizado y prudente de las drogas sino que posiblemente lo promueva. Además la cultura recreativa ocupa un lugar central y en expansión en nuestra sociedad. Las actividades de ocio, la diversión, la búsqueda de placer, son algunas de las características que mejor definen a la sociedad de principios del siglo XXI, que se relaciona con el consumo y con la definición de la identidad y el estatus de los ciudadanos y en especial los jóvenes. Hemos analizado anteriormente la intensidad con que los jóvenes participan en estas prácticas recreativas. El consumo de drogas, en especial las denominadas recreativas, no se puede abordar en nuestras sociedades al margen de analizar la influencia de la cultura recreativa. De ahí que la prevención actual dificilmente pueda sustraerse de este debate cultural, incluso la que no va dirigida directa y especificamente al contexto recreativo. La prevención no puede entenderse pues como un instrumento aséptico que se aplica sobre una determinada realidad y que funciona independientemente de la lógica cultural. Un ejemplo claro lo tenemos con la prevención del tabaquismo que empieza con la constatación empírica hace unas décadas de que el consumo del tabaco produce con el paso de los años una serie de problemas. Se ponen en marcha programa preventivos escolares que tratan de estimular el no consumo por parte de los adolescentes. Pero el gran éxito de este tipo de prevención corre paralelo al gran debate -y a las medidas que ello genera- que se crea sobre el tabaquismo desde un punto de vista económico, sanitario, legal, publicidad, derechos de los individuos, protección de los menores, etc. Es decir, que se va más allá de lo estrictamente sanitario e individual, para entrar en lo cultural, en lo económico y en lo político.

Cada sociedad en cada momento histórico analiza -o debería analizar- el lugar que deben ocupar las diversas drogas en su dinámica interna. En el pasado las drogas han estado presentes en muchas culturas, pero en general, si exceptuamos el alcohol y el tabaco, su presencia y su sentido ha sido poco central, muy ritualizado y muy ocasional. Pero se están dando unas circunstancias en la sociedad actual que son totalmente novedosas. Existe abundancia y diversidad de oferta de drogas, los potenciales consumidores son cada vez más numerosos, son jóvenes y tienen una elevada disponibilidad económica, existe una dinámica comercial tanto para las drogas legales como para las ilegales que potencia su consumo, la sociedad en general está cada vez más orientada hacia la búsqueda del placer y del consumo, entre otras posibles razones que explican y diferencian la situación actual de cualquier otra que se haya vivido en esta sociedad en el pasado o en cualquier otra sociedad. Todo ello hace que sea cada vez más complicado para los ciuda- 
danos y para la sociedad global analizar esta situación tan nueva, tan cambiante y que se presenta bajo una apariencia tan seductora, y establecer el adecuado balance sobre los riesgos que se quieren asumir. Es esta precisamente una característica de los tiempos modernos, a saber, la dificultad para ver los riesgos ocultos en las prácticas actuales. Ulrich Beck (1992) se refiere a esa característica de los riesgos en la sociedad moderna cuando analiza los riesgos de tipo medioambiental o las alteraciones químicas de los alimentos. Muchos de estos riesgos se escapan de la capacidad de análisis del ciudadano medio y solo son detectables por expertos en cada una de las ramas científicas en cuestión. Cuando se trata de riesgos sociales también debemos suponer que pueda ocurrir algo parecido; son riesgos que a pesar de ser creados por el estilo de vida propio de los ciudadanos, existen cada vez más variables que son difíciles de ser tenidas en cuenta por los ciudadanos, de aquí la necesidad de que los expertos en ciencias sociales ayuden a desentrañar los fenómenos sociales actuales. Es el caso del consumo de drogas en ambientes recreativos sobre lo que existe una baja percepción de la problemática que engendra, hay grandes dificultades para entender como y porque se está potenciando este uso y no es fácil saber como intervenir preventivamente. Lo que sí sabemos es que para que un riesgo o peligro sea detectable y visible debe estar socialmente definido, explicado y asumido como tal. Para ello la labor de los expertos juega un papel primario y básico, y posteriormente los medios de comunicación contribuyen a su definición y transmisión social.

Pero es evidente que todavía en el terreno de la prevención en Europa estamos lejos de esta situación ideal en que los expertos han tenido ocasión de investigar y de emitir sus análisis, cuando por otro lado la situación del uso y abuso de drogas es más interdependiente entre los distintos estados miembros de la Unión Europea, pues las modas juveniles se expanden con relativa facilidad a través de las fronteras. No existe la inversión nece- saria en medios económicos y personales para avanzar en conocimientos y consenso sobre las políticas y prácticas preventivas, cuando paradojicamente existe cada vez más capacidad de la industria recreativa en afianzar su capacidad e incluso proponer nuevas formulas recreativas (por ejemplo la 'Love parade' de Berlín se extiende progresivamente a otras ciudades europeas) e incluso crecen los intereses europeos en mantener el mercado de drogas al convertirse ella misma en productora de drogas de síntesis. Esta falta de conocimientos y de consenso entre los profesionales facilita que no exista una verdadera política preventiva de estado y nos conformemos con la aplicación de programas preventivos puntuales -normalmente realizados sin mucha efusión de medios- centrados sobretodo en el campo escolar y, con todavía menos frecuencia e intensidad, en el campo comunitario o familiar. No obstante, conviene interpretar adecuadamente estas insuficiencias profesionales, pues son el resultado la mayor parte de las veces de la falta de interés de la misma sociedad y de sus políticos, que no apuestan por este tipo de políticas.

La situación española en el campo de la prevención desde un punto de vista profesional se podría pensar que fue hace años más avanzada que otros países europeos. Pero posiblemente se esté produciendo un estancamiento motivado porque no parece que en general las políticas autonómicas -salvo honrosas excepciones- estén apostando por la prevención y, por otro lado, existe una mayor dificultad para adoptar programas que han demostrado su eficacia y de esta manera facilitar su generalización, pues en ocasiones cada autonomía prefiere tener sus propios programas. En cuanto a la incorporación a Europa puede "suponer un mayor contacto entre los profesionales y responsables de políticas preventivas de diversos países. Ello puede tener una parte enriquecedora por el acumulo de experiencias, pero también puede llevar a adoptar formulas de compromiso demasiado generales y abstractas buscando lugares comunes con los que todo el mundo se pueda identificar y que no hieran 
susceptibilidades individuales, lo cual no es necesariamente positivo pues puede quedar en simples declaraciones de principios, difíciles de operativizar, y que luego no llevan a ninguna parte. Para no caer en estar trampas esterilizantes va a ser necesario llegar a compromisos operativos que hagan justicia a las peculiaridades culturales y las idiosincrasias locales sin perder la capacidad de generalizar y actuar" (Calafat A 1998).

Una de las aportaciones españolas en cuanto a la prevención recreativa es el desarrollo, como ya se ha dicho, en bastantes ciudades españolas de actividades nocturnas preventivas alternativas a la habitual actividad recreativa desarrollada por la industria. Son actividades relativamente estructuradas y que llevan unos años aplicándose en nuestro país, por lo que dedicaremos algunos comentarios a analizar la situación. En general se trata de programas que tienen pocos objetivos específicos de prevención de drogas. La mayoría de ellos presenta objetivos demasiado generales como promoción de la salud o proporcionar alternativas de ocio como factor de protección. Pero, si nos vamos a la literatura científica, no se ha podido demostrar que de por sí estos programas (organizar e involucrar a los jóvenes en actividades artísticas, deportes, diversión, etc) disminuyan el consumo de sustancias de acuerdo a una revisión hecha por Norman (Norman et al. 1997). En el mismo sentido una revisión de 45 programas evaluados de diversa índole (Hansen 1992) resulta que casi todos los programas dan resultados positivos excepto los que se basan en proporcionar experiencias alternativas, es decir, desarrollan actividades que son incompatibles con el uso de sustancias. Ello no significa necesariamente que vaya a ocurrir lo mismo si se evaluasen los programas españoles de ocio alternativo pues evidentemente no se trata de los mismos programas alternativos, ni de la misma situación cultural ni de los mismos consumidores, pero estos antecedentes evaluados deben servir para actuar con cautela, especialmente porque este tipo de programas no son tan alternativos como indican, pues no ponen en cuestión la misma lógica que mantiene la actividad recreativa nocturna propiciada por la industria.

$Y$, en efecto, en una interesante evaluación de resultados y que sigue una lógica experimental -se trata en este caso del programa 'Abierto hasta el amanecer'- en que se ha utilizado un grupo control, los autores (Secades 2003) concluyen que "no se han observado diferencias significativas en las variables medidas en el seguimiento entre los participantes en el programa y el grupo control" ni en el consumo a corto plazo de alcohol y otras drogas, ni en el cambio de actitudes y hábitos, a excepción lógicamente del espacio de tiempo en el que se asiste a las actividades donde, por definición, no se oferta alcohol y se supone que hay más control para la venta de otras drogas. Por otro lado señalan que los jóvenes con mayor problema de conducta de abuso no suelen acudir a este tipo de actividades. Señalamos por último que los mismos jóvenes evaluados para este estudio hacen una valoración subjetiva del programa muy positiva y creen que las actividades programadas son muy interesantes y que lo recomendarían a sus amistades. Y esta última afirmación nos sirve para introducir porque se emplean y se expanden programas cuya eficacia no está demostrada o incluso que está demostrado que no existe.

Nos puede servir de referencia un somero análisis de lo que ocurre en el campo de la prevención escolar, que es un campo más controlable y donde hay programas preventivos evaluados que han demostrado su eficacia. Nos encontramos en 1.999 que de 1.900 escuelas secundarias de Estados Unidos revisadas sólo una de cada 4 utilizaban programas preventivos que hubiesen sido evaluados, cuando desde 1.998 existe la obligación de utilizar tal tipo de programas para que la escuela pueda recibir dinero federal para su desarrollo (Ringwalt et al 2002). En otro estudio (Ennett et al 2003) con 1.905 escuelas norteamericanas, la mayor parte de secundaria, ocurre que también una mayoría no utilizan programas evaluados -más de la mitad siguen utilizando el programa DARE que las 
evaluaciones han demostrado que no es eficaz-, pero además sólo un $21 \%$ de los profesores o de las personas encargadas de dar el programa lo utilizaban adecuadamente de forma interactiva. En conclusión, según este estudio, sólo una de cada siete escuelas están dando programas que hayan demostrado ser efectivos y los están dando de forma eficaz. Por tanto no es una cuestión secundaria dentro de la prevención escolar -y posiblemente con más razón en un campo como el recreativo mucho más nuevo, con menos investigación y evaluación y con bastante ideologización y militancia- preocuparse porque se promocionen programas preventivos que sean eficaces o científicos. En este sentido parece oportuno traer a colación los comentarios de Nancy Tobler (1997) autora de dos metanálisis en 1986 y 1993 de programas preventivos acerca de porque se siguen utilizando programas preventivos que no sirven, referido todo ello a la situación americana. Las razones aducidas son varias. Por un lado no se estaría haciendo una promoción suficiente y eficaz de los programas que han sido evaluados. Por otro lado, los programas interactivos - que requieren una pedagogía activa por parte del profesorado en el caso de los programas escolares- que, de acuerdo con el metanálisis realizado, serían significativamente los más eficaces, son los más difíciles y caros de aplicar. Esta necesidad de una pedagogía activa entronca con otra explicación de porque se siguen utilizando programas obsoletos que sería la falta de formación - y a veces también de tiempo y motivación- en estas técnicas por parte de los profesores. Pero existen todavía otras explicaciones de índole muy distinta como la dificultad para volver sobre los propios pasos y aceptar que un programa que se ha venido aplicando no tiene prácticamente efecto sobre el consumo de sustancias de los jóvenes. Todos podemos ver claramente las graves implicaciones políticas que existen en aceptar que lo que se venía haciendo no servía para nada en el mejor de los casos, especialmente si existía una importante implicación de la comunidad en el programa. Por otro lado, existe en muchos de nosotros la convicción, necesaria para poder seguir trabajando, de que lo que venimos haciendo funciona positivamente, lo cual nos quita poder crítico para volver sobre nuestros pasos. Tener en cuenta estas reflexiones en el terreno de la prevención recreativa parece totalmente pertinente.

Existe amplio consenso científico en que la prevención para ser efectiva debe ser interactiva (Tobler 1997; Tobler et al 2000)y que deben ser multimodales aprovechando la sinergia de las diversas actuaciones (Dorn \& Murji 1992;Martín 1997;Sloboda 1994) y que se extiendan en el tiempo, además de muchas otras consideraciones prácticas que han encontrado su validación empírica ¿Por qué entonces este interés en promocionar medidas aisladas, no interactivas, como el pill testing o algunas otras medidas cuando claramente tienen que ser ineficaces a la luz de la investigación actual? ¿Para facilitar información sobre el contenido de las pastillas a los usuarios? Existen dudas de la fiabilidad de los métodos de detección empleados in situ (Winstock, Wolff \& Ramsey 2001), pues pueden proporcionar un sentido excesivo de seguridad y por otro lado estudios en diversos países como Inglaterra u Holanda la calidad de las pastillas es bastante buena, estando el peligro de su uso -en contra de la creencia frecuente entre los usuarios y los medios de comunicación- precisamente en su buena calidad y no en la adulteración. Ello no supone una crítica a los programas de reducción del riesgo ni a esta orientación, pero si una llamada a la necesidad de que los programas que se apliquen sigan una lógica acorde con los avances científicos. Partiendo de este consenso científico se aplica un programa comunitario realizado desde la perspectiva de la reducción del riesgo en seis comunidades de Massachussets aplicando sinérgicamente una serie de medidas (campaña mediática, educación entre pares en la escuela y otros diversos programas preventivos) en relación con conducir y beber con el resultado de un descenso después de 5 años del $39 \%$ de accidentes mortales respecto al resto del estado entre conductores de 15 a 25 años y un $40 \%$ menos de jóvenes de 16 
a19 años que informaban de haber conducido habiendo bebido el último mes (Hingson et al. 1996)

\section{Prioridades preventivas.}

Desde Irefrea hemos venido elaborando una serie de prioridades que tienen en cuenta tanto los datos recogidos en los diversos estudios sobre los jóvenes que consumen drogas recreativas (Calafat A et al. 2001;Calafat $A$ et al 2003; Calafat et al. 1997; Calafat et al 1998;Calafat et al 1999;Calafat et al 2000; Calafat, Sureda, \& Palmer 1997) como el estado de la investigación sobre la prevención. Veremos que lo que proponemos no son programas específicos sino políticas amplias, pero al mismo tiempo concretas, y que sean capaces de influir sobre la forma en que se está construyendo la actividad recreativa de fin de semana. Estas propuestas son las siguientes:

1. Retrasar la edad de inicio de los adolescentes en las actividades recreativas que más se asocian al consumo de drogas.

Uno de los factores de riesgo con mayor valor predictivo sobre el abuso de drogas es iniciarse tempranamente en su uso. La edad en que los jóvenes se inician en la actividad de salir de marcha es crucial pues, en la situación actual, está muy ligada a una determinada cultura que promueve el uso de drogas. Retrasar su ingreso en estos ambientes tendrá repercusiones sobre su consumo. Ello implica necesariamente a la familia y el cumplimiento de las medidas administrativas que retrasan la entrada de los menores de edad a ciertos locales. También implica la existencia de una oferta de ocio suficiente y atractiva no ligada a la oferta nocturna de fin de semana de la industria.

Al mismo tiempo hay que replantearse cual es el momento más adecuado para hacer la prevención (no nos referimos aquí precisamente a la recreativa, sino sobre todo a la escolar). Con frecuencia se habla en función de algunos factores de riesgo la necesidad de adelantar la prevención al máximo posible para poder influir en la cadena causal. Pero, sin que ello deje de ser cierto, la importancia que están adquiriendo las prácticas recreativas y el porcentaje elevado y creciente de jóvenes que se involucran en dichas prácticas, entendemos que el acento hay que ponerlo en estos años en que los adolescentes y jóvenes comienzan a involucrarse activamente en estas prácticas, pues es en estos momentos en que los adolescentes y jóvenes toman decisiones sobre sus pautas de uso y abuso de sustancias. En especial interesa conocer mejor los momentos de transición en los cuales los jóvenes asumen, abandonan o consolidan pautas de abuso. Por consiguiente hay que concentrar esfuerzos en conocer mejor estos momentos de transición, y en concreto el de la adolescencia tardía o adultez temprana donde ya se pueden fijar conductas de abuso o, por el contrario, pueden abandonarse (Kandel 1998; White, Bates, \& Labouvie 1998). Es en estos momentos precisamente donde hay que reforzar la actividad preventiva de forma que el joven no consumidor o consumidor experimental esté en condiciones de poder explicar positivamente su posición.

2. Las estrategias preventivas deben no sólo adecuarse sino también influir sobre las subculturas juveniles.

Si somos conscientes de la gran fuerza que tiene sobre los jóvenes la cultura recreativa actual, las estrategias no deben crearse pensando únicamente en el impacto individual sino más bien en el ambiente; deberían influir en los medios de comunicación, sobre la música, la publicidad, los elementos simbólicos que llegan a los jóvenes. En estos momentos la industria recreativa, la alcoholera, la tabaquera e incluso la organización que soporta el consumo de drogas ilegales son los que elaboran o facilitan la creación de muchos de estos contenidos que son trans- 
cendentales para los jóvenes. Para los jóvenes la moda es un elemento de gran importancia en su toma de decisiones hasta el punto que buena parte de ellos afirman consumir drogas ilegales porque están de moda (Kemmesies 2000). De ahí la insuficiencia de algunas propuestas de reducción del daño pues no cuestionan la misma lógica de la cultura recreativa. Sin conseguir una colaboración a fondo de la industria -y no sólo en aspectos accesorios- la prevención será poco eficaz. Ello implica una labor importante por parte de los profesionales de la prevención en identificar los aspectos conflictivos y en conseguir una cierta complicidad de la sociedad en sus planteamientos.

\section{Se debe prestar atención al género como} vehiculizador del consumo.

En los países europeos estamos asistiendo al progresivo aumento del consumo entre la población femenina. Las diferencias de género definidas en términos de desigualdades ha permitido que en las últimas décadas se elaboren políticas de igualdad unidireccionales. Es decir, orientadas a que las mujeres accedan a espacios masculinos que han sido, a través de la historia, valorados muy en positivo como es el consumo de drogas $y$, en especial, el tabaco y el alcohol. La actividad preventiva puede contribuir a elaborar un discurso de género más íntegro, menos androcéntrico, otorgando valores positivos al mundo femenino e invitando a los varones a que aprendan un poco más, por lo menos en cuestiones de drogas, de sus compañeras, y que éstas imiten un poco menos a los varones.

\section{La socialización y la búsqueda del éxito} social debería estar menos ligada al consumo de drogas.

En la actualidad el consumo, la posesión, el uso y el abuso de drogas actúan como elementos de la carrera hacia el éxito social para muchos jóvenes dentro de la lógica cultural actual. Ello viene facilitado porque es en gran parte la burguesía la que con más intensidad acude a estos espacios recreativos, elaborando así los estándares sociales. Tener éxtasis o cocaína en el bolsillo para invitar a los amigos actúa como un elemento de prestigio, al igual que tener un coche caro o vestir con indumentaria de marca. Las drogas son sustancias muy coherentes con el estilo consumista de nuestra sociedad y se adaptan a ella. Consumir drogas ayuda a incrementar la actividad para ser más sociable, más expansivo, más innovador y atrevido, o sea, prosperar según los baremos actuales que se vinculan al éxito social. Todo ello es también parte del nuevo etiquetaje incorporado a las sustancias y que debe ser deconstruido o por lo menos cuestionado en los programas de prevención.

5. Revisar las formas de relación entre adultos y jóvenes para que se adecuen al nuevo formato en que los jóvenes se divierten y consumen drogas.

No es fácil actualmente para los padres, profesores y adultos en general tener una visión balanceada y crítica sobre la juventud y el uso de drogas recreativas. Para muchos adultos la posibilidad de tener tiempo libre, de acceder a los placeres de la diversión recreativa, de vivir la juventud despreocupadamente, de tener un cierto grado de libertad individual, etc., fue algo de lo que carecieron en su juventud o fue el resultado de una ardua conquista personal y social. Sin embargo para un sector importante de los jóvenes actuales -en especial el que más participa de las actividades recreativas nocturnas de fin de semana- su dificultad está en como gestionar una abundancia de estímulos y posibilidades, proveída por la industria recreativa que les interesa mantener a los adolescentes y los jóvenes bajo su 'tutela'. La industria es la gran interesada que desde edades muy tempranas existan espacios diferenciados de diversión para los adolescentes y jóvenes y los adultos, pues conocen todo el potencial de consumo de los jóvenes.

La prevención de drogas, las políticas juveniles, sociales y familiares, deberían llevar a 
facilitar más espacios de encuentro intergeneracionales.

6. Necesidad de establecer un consenso en el ámbito científico y profesional sobre el significado y la prevención de los consumos recreativos.

La actuación preventiva ante las drogas en ámbitos recreativos se ha incrementado, pero también se constata que existe escasa investigación sobre las bases científicas para construir dichos programas y una falta de evaluación de las acciones. La mayoría de los proyectos preventivos son puntuales y consisten en proveer información a los jóvenes. Es frecuente que estos proyectos no se apoyen en modelos teóricos explicativos y conocidos y que no se tengan en cuenta otras experiencias anteriores evaluadas en el campo de la prevención.

Debe existir un mayor debate científico -y no tan sólo ideológico- que debe apoyarse en la construcción de un modelo teórico, en el conocimiento de los factores de riesgo y la evaluación de los programas preventivos. Es necesario que en Europa se centren energías en investigar la cultura y las prácticas recreativas, evaluar programas y construir modelos de acuerdo a nuestra realidad cultural.

7. Elaboración de información específica sobre los efectos de las drogas legales e ilegales.

En la investigación aparece como dato sorprendente la desinformación sobre los efectos y consecuencias del consumo de drogas en los jóvenes -en especial sobre los efectos negativos. En la parte cualitativa (grupos de discusión y entrevistas en profundidad) del estudio de Irefrea (Calafat et al 2001) entre jóvenes clubbers el equipo investigador de Liverpool señalaba que había mucha falta de información sobre los riesgos físicos y legales de las drogas. La mayoría de los participantes hablaban poco de los riesgos agudos, y solían identificar el riesgo principalmente con el uso prolongado. El nivel de conocimiento de los peligros asociados al MDMA era muy bajo y tenían grandes dificultades para identificar riesgos asociados a las drogas legales como el tabaco o los popper.

Bien se sabe que disponer de información no supone automáticamente la adopción de cambios comportamentales. Pero desde luego más difícil es que alguien se plantee algún cambio en su vida si no tiene la más mínima información sobre la necesidad de hacerlo. Proponemos que haya más información disponible para los jóvenes, que tengan en cuenta las diversas sustancias, en especial las más consumidas como el tabaco, el alcohol y el cannabis. Obviamente esta información debe acompañarse de otras medidas preventivas. No se debe olvidar que esta información debe ser repetida -con las modificaciones necesarias- con una cierta periodicidad pues cada año se incorporan nuevos jóvenes a la vida social y recreativa.

8. Elaboración de estrategias que aumenten la percepción del riesgo. Esta estrategia no debe verse como incompatible con la reducción de riesgos en los consumidores recreativos.

Actualmente son mayoría aquellos programas preventivos centrados en la "reducción del daño». Presuponen que es difícil cambiar los hábitos de consumo y, en consecuencia, sólo se plantean actuar para disminuir los problemas ligados a estos consumos. Esta estrategia puede tener algún sentido aisladamente sólo si nos referimos exclusivamente a grupos de muy alto riesgo, pero precisamente porque son un grupo difícilmente alcanzable y poco permeable al cambio, sería un error centrar todas las energías preventivas en ellos. Es muy importante actuar sobre la mayoría de jóvenes que no se encuentran todavía en situación de alto riesgo aumentando su conocimiento sobre los problemas derivados del uso de drogas, dotándolos de capacidad críticas y de habilidades para manejarse en situaciones recreativas.

9. Intentar que el no consumo o el consumo moderado sea una opción culturalmente aceptada en los ambientes recreativos. 
Estamos ante una situación en que parece que lo "culturalmente correcto» es divertirse al máximo y consumir. Ello responde a una lógica cultural de una sociedad consumista, pero también a intereses económicos de la industria de la diversión que alimenta esta visión. Existe no obstante un sector importante de la juventud que no sigue estas pautas y que se sienten poco legitimados culturalmente, como si estuviesen haciendo algo incorrecto. Es importante apoyar una "cultura de la moderación" o de la contención, para que los jóvenes puedan realmente elegir, y de esta forma ser más libres (Calafat et al, 2003).

Al igual que ni los jóvenes ni los consumidores son un grupo homogeneo tampoco lo son los no consumidores. A grandes rasgos podemos diferenciar dos grandes sub-grupos. Por un lado tendríamos a la élite, formada por un grupo de jóvenes con buenas habilidades sociales, que de forma consciente y clara deciden no consumir como una opción, mientras que por otra lado estaría otro tipo de no consumidores cuya situación de no consumo responde en parte a dificultades en lo personal y en lo relacional, como pueden ser menos necesidades sociales, menos curiosidad, temores, ... (Evans \& Skager 1992). Unos y otros necesitan distintos apoyos sociales para mantener su actitud abstemia y para sentirse legitimados ante sus coetáneos.

10. Crear contextos recreativos en que las condiciones medioambientales sean más saludables, implicando para ello a la industria recreativa.

Una parte importante de los problemas derivan de las condiciones físicas u organizativas de los ambientes en que tiene lugar la diversión. Nos referimos a salidas de emergencia adecuadas, temperatura altas en los locales, exceso de personas, entrenamiento del personal de las discotecas en evitar problemas y atender urgencias, disponibilidad de bebidas no alcohólicas a bajo precio, existencia de dispensadores de preservativos, transporte público adecuado, etc. Es importante crear una dinámica de colaboración entre la administración y la industria de la diversión.

Pero esta colaboración debe ir más lejos, puesto que la socialización de una parte importante de la juventud está en manos de la industria recreativa. Se deben trabajar formulas de colaboración creativas y convincentes que permitan a los jóvenes no estar tan capturados por el modelo hegemónico de diversión de fin de semana.

\section{REFERENCIAS}

Arthur, M., Hawkins, J. D., Catalano, R. F., \& Pollard J A 1997, Student Survey of Risk and Protective Factors and Prevalence of Alcohol, Tobacco \& Others Drugs Use, No publicado.

Bachman J G, Johnston LD, \& O'Malley P M. Explaining Recent Increases in Students' Marijuana Use: Impact of Perceived Risks and Disapproval, 1976 through 1996. Am.J.of Public Health 88[6]. 1998.

Bachman J G, O'Malley P M, Schulenberg J E, Johnston L D, Bryant A L, \& Merline A C 2002, The decline of substance use in young adulthood. Changes in social activities, roles and beliefs Lawrence Erlbaum Associates, Mahwah, NJ.

Bandura A 1986, Social Foundations of Thought and Action: A Social Cognitive Theory Prentice Hall, New York.

Beck U 1992, Risk society. Towards a new modernity Sage, London.

Beck, J. 1993, "Ecstasy and the rave scene: historical and cross-cultural perspectives.", Proceedings, vol. 2, pp. 424-431.

Beck, J. \& Watson, L. 1991, "New Age Seekers: MDMA Use as an Adjunct to Spiritual Pursuit.", J.of Psychoactive Drugs, vol. 23, no. 3, pp. 261-270.

Becoña, E. 2002, Bases científicas de la prevención de las drogodependencias Plan Nacional sobre Drogas, Madrid.

Bloomfield 2002, "Alcohol Consumption and alcohol Problems among Women in European Countries," en Neue Therapieansätze bei Alkoholproblemen, Maan, ed., Pabst Science Publishers, Berlin. 
Burkhart G \& López M. Party Setting Projects from EDDRA. 2002. http://eddrapdf. emcdda.org/ eddra_party_settings.pdf

Calafat A 1998, "Hacia una prevención institucionalizada y científica", Adicciones, vol. 10, no. 4, pp. 291-297.

Calafat A, Fernández C, Juan M, Anttila A, Arias R, Bellis MA, Bohrn, K., Fenk R, Hughes, K., Kerschl A V, Kokkevi A, Kuussaari K, Leenders F, Mendes F, Siamou I, Simon, J., van de Wijngaart, G., \& Zavatti P 2003, Enjoying the nightlife in Europe. The role of moderation Irefrea, Palma de Mallorca.

Calafat A, Fernández C, Juan M, Bellis MA, \& et al 2001, Risk and control in the recreational drug culture Irefrea, Palma de Mallorca.

Calafat, A., Amengual, M., Palmer, A., \& Saliba, C. 1997, "Drug Use and Its Relationship to Other Behavior Disorders and Maladjustment Signs among Adolescents.", Substance Use and Misuse, vol. 32, no. 1, pp. 1-24.

Calafat, A., Bohrn, K., Juan M, Kokkevi A, Maalsté, N., \& et al 1999, Night life in Europe and recreative drug use. Sonar 98. IREFREA, Palma de Mallorca.

Calafat, A., Juan M, Becoña, E., \& et al 2000, Salir de marcha y consumo de drogas Plan Nacional sobre Drogas, Madrid.

Calafat, A., Stocco, P., Mendes, F., Simon, J., van de Wijngaart, G., Sureda, P., \& et al 1998, Characteristics and Social Representation of Ecstasy in Europe. IREFREA, Palma de Mallorca.

Calafat, A., Sureda, P., \& Palmer, A. 1997, "Características del consumo de éxtasis en una muestra de universitarios y usuarios de discoteca", Adicciones, vol. 9, no. 4, pp. 529-555.

Collin, M. 1997, Altered State: The Story of Ecstasy Culture and Acid House Serpent's Tail, London.

Cummings $\mathrm{K}$ M, Becker M H, \& Maile M 1980, "Bringing the models together: an empirical approach to combining variables used to explain health actions", Journal of Behavior Medicine, vol. 3, pp. 123-145.

Dorn, N. \& Murji, K. 1992, Drug prevention: a review of the English language literature Crown, London.

EMCDDA 2002, Informe anual sobre el problema de la drogodependencia en la Unión Europea y en Noruega EMCDDA, Lisboa.
Ennett, S. T. \& et al 2003, "A comparison of current practice in school-based substance prevention programs with meta-analysis findings", Prevention Science, vol. pendiente publicación.

Evans W P \& Skager R 1992, "Academically successful drug users: an oxymoron?", J.of Drug Education, vol. 22, no. 4, pp. 353-365.

Forsyth, A. J. M., Barnard, M., \& McKeganey, N. 1997, "Musical preference as an indicator of adolescent drug use", Addiction, vol. 92, no. 10, pp. 1317-1325.

Gamella, J. F., Alvarez Roldán, A., \& Romo Avilés, N. 1997, "La "fiesta" y el "éxtasis" drogas de síntesis y nuevas culturas juveniles", Revista de Estudios de Juventud no. 40, pp. 17-36.

García, D. Marihuana y nuevas músicas. Cáñamo Agosto[20], 24-26. 1999.

Gardner S E, Brounstein P J, Stone D B, \& Winner C 2001, Guide to science-based practices. 1 Science-based substance abuse prevention. Substance Abuse and Mental Health Services Administration. Center for Substance Abuse Prevention, Rockville, MD.

Grund, J. P. 1993, Drug use as a social ritual IVO series 4, Rotterdam.

Hammersley R, Khan F, \& Ditton, J. 2002, Ecstasy and the rise of the chemical generation Routledge, London.

Hansen W B. 1992, "School-based substance abuse prevention: a review of the state of the art in curriculum 1980-1990", Health Education Research, vol. 7, pp. 403-430.

Hawkins J, Catalano R F, \& Miller JY 1992, "Risk and Protective Factors for Alcohol and Other Drug Problems in Adolescence and Early Adulthood: Implications for Substance Abuse Prevention", Psychological Bulletin, vol. 112, no. 1, pp. 64-105.

Hingson, R., McGovern T, Howland J, Heeren T, Winter, M., \& Zakocs R 1996, "Reducing alcohol-impaired driving in Massachusetts: The Saving Lives Program", Am.J.of Public Health, vol. 86, pp. 791-797.

Kandel DB 1998, "Persistent themes and new perspectives on adolescence use: A lifespan perspective," en New perspectives on adolescent risk behavior, Jessor R, ed., Cambridge University Press, Cambridge, pp. 43-89.

Kemmesies, U. 2000, "User of illicit drugs in the 'civil' milieu: on the influence of formal and informal social control -preliminary finding of a 
pilot study-", Originalbeiten, vol. 46, no. 2, pp. 101-110.

Kokoreff, M. \& Mignon, P. 1994, La production d'un problème social: drogues et conduites d'excès. La France et l'Angleterre face aux usagers d'ecstasy et de cannabis., DGLDT/ Min.Rech.et Ens.Sup., Paris.

Kumpfer K L, Szapocznik, J., Catalano R F, Clayton, R., Liddle H A, Mcmahon R, Millman J, Orrego M E V, Rinehart N, Smith I, Spoth R, \& Steele $M$ 1998, Preventing substance abuse among children and adolescents. Family-centered approaches Department of Health and Human Services. Center for substance abuse prevention, Rockville, MD.

Martín E 1997, "La prevención en España hoy: propuestas de consenso institucional, técnico y social," in Prevención de las drogodependencias. Análisis y propuestas de actuación, Ministerio del Interior. Plan nacional sobre Drogas, Madrid, pp. 67-84.

Megías Quirós I. \& Rodríguez San Julián E. 2001, La identidad juvenil desde las afinidades musicales Instituto de la Juventud (INJUVE), Madrid.

Norman E, Turner S, Zunz S J, \& Stillson K 1997, "Prevention programs reviewed: what works?," in Drug-free youth: A compendium for prevention specialists, Norman E, ed., Garland Publishing, New York, pp. 22-45.

Parker, H., Aldridge, J., \& Measham, F. 1998, Illegal Leisure. The normalization of adolescent recreational drug use Routledge, London.

Petraitis, J., Flay, B. R., Miller, T. Q., Torpy, E. J., \& Greiner, B. 1998, "Illicit substances use among adolescents: a matrix of prospective predictors", Substance Use and Misuse, vol. 33(3), pp. 2561-2604.

Petterson P L, Hawkins, J. D., \& Catalano, R. F. 1992, "Evaluating comprensive community drug risk reduction interventions. Design challenges and recommendations", Evaluation review, vol. 16, pp. 579-602.

Plan Nacional sobre Drogas 2002b, Observatorio Español sobre drogas. Informe $n^{\circ} 5$ Plan Nacional sobre Drogas, Madrid.

Plan Nacional sobre Drogas 2002a, Observatorio Español sobre drogas. Informe $n^{\circ} 5$ Plan Nacional sobre Drogas, Madrid.

Ringwalt C \& et al 2002, "The prevalence of effective substance abuse prevention curricula in U.S. middle schools.", Prevention Science, vol. 2, no. 4, pp. 257-265.

Robles L \& Martínez J M 1998, "Factores de protección en la prevención de las drogodependencias", Idea-Prevención, vol. 17, no. juliodiciembre, pp. 58-69.

Rogers RW 1984, "Cognitive and physiological processes in fear appeals and attitude change. A revised theory of protection motivation," in Social Pschophysiology, Cacioppo JT \& Petty R E, eds., Guilford Press, New York, pp. 153176.

Secades Villa R. 2003, Diseño y aplicación de un procedimiento de evaluación de programas de prevención comunitaria de drogodependencias que desarrollan actividades alternativas de ocio en población de riesgo (abierto hasta el amanecer), Sin publicar.

Sloboda Z 1994, "El estado actual de la investigación sobre la prevención del abuso de drogas en los Estados Unidos: mirando hacia el año 2000," en XXI Jornadas Nacionales Socidrogalcohol. Ponencias y comunicaciones, Socidrogalcohol, Madrid.

The European Opinion Research Group 2002, Attitudes and Opinions of young people in the European Union on drugs., European Commission, Eurobarometer 57.2.

Tobler N S 1997, "Meta-Analysis of Adolescence Drug Prevention Programs: Results of the 1993 Meta-Analysis," en Meta-Analyisis of Drug Abuse Prevention Programs, W. J. Bukoski, ed., NIDA, Rockville, MD, pp. 5-68.

Tobler N S, Roona MR, Ochshorn P, Marshall D G, Streke A V, \& Stackpole K M 2000, "Schoolbased adolescent drug prevention programs: 1998 meta-analysis", Journal of Primary Prevention no. 20, pp. 275-336.

Tossmann, P., Boldt, \& Tensil 2001, "Demand Reduction Activities in the Field of Synthetic Drugs in the European Union," en Risk and Control in the recreational drug culture, IREFREA, Palma de Mallorca, pp. 285-314.

van de Wijngaart, G., Braam, R., De Bruin, D., Fris, M., Maalsté, N., \& Verbraeck, H. 1997, Ecstasy in het uitgaanscircuit. Een sociaal-epidemiologisch onderzoek naar de aard, omwang en risico's van het gebruik van XTC en andere uitgaansdrugs op houseparty's. Brouwer Uihof BV, Utrecht.

Webster R, Goodman M, \& Whalley G. Safer clubbing. Guidance for licensing authorities, club 
managers and promoters. 2002. London, Drug Prevention Advisory Service.

Weinstein N D 1993, "Testing four competing theories of health-protective behavior", Health Psychology, vol. 12, pp. 324-333.

White, H. R., Bates, M. E., \& Labouvie, E. W. 1998, "Adult outcomes of adolescent drug use: A comparison of process-oriented and incremental analysis," in New perspectives on adolescent risk behavior, Jessor $\mathrm{R}$, ed., Cambridge University Press, Cambridge, pp. 55-181.

Winstock A R, Wolff K, \& Ramsey J 2001, "Ecstasy pill testing: harm minimization gone too far?", Addiction, vol. 96, pp. 1139-1148. 
